US Army Corps

of Engineers ${ }_{\circledast}$

Engineer Research and

Development Center

Meteorological Property and Temporal

Variable Effect on Spatial Semivariance of Infrared Thermography of Soil Surfaces for Detection of Foreign Objects

Austin K. Workman and Jay L. Clausen

June 2021 
The U.S. Army Engineer Research and Development Center (ERDC) solves the nation's toughest engineering and environmental challenges. ERDC develops innovative solutions in civil and military engineering, geospatial sciences, water resources, and environmental sciences for the Army, the Department of Defense, civilian agencies, and our nation's public good. Find out more at www.erdc.usace.army.mil.

To search for other technical reports published by ERDC, visit the ERDC online library at https://erdclibrary.on.worldcat.org/discovery. 


\section{Meteorological Property and Temporal Variable Effect on Spatial Semivariance of Infrared Thermography of Soil Surfaces for Detection of Foreign Objects}

Austin K. Workman and Jay L. Clausen

Cold Regions Research and Engineering Laboratory

U.S. Army Engineer Research and Development Center

72 Lyme Road

Hanover, NH 03755

Final report

Approved for public release; distribution is unlimited.

\footnotetext{
Prepared for U.S. Army Corps of Engineers

Washington, DC 20314

Under ERDC T-15
} 


\section{Preface}

This study was conducted for the US Army Corps of Engineers under ERDC T-15 funding. The technical monitor was Dr. Jay Clausen.

The work was performed by the Biogeochemical Sciences Branch (Mr. David B. Ringelberg, Acting Chief) of the Research and Engineering Division (Dr. George Calfas, Chief), U.S. Army Engineer Research and Development Center, Cold Regions Research and Engineering Laboratory (ERDC-CRREL). At the time of publication, the Deputy Director of ERDCCRREL was Mr. David B. Ringelberg, and the Director was Dr. Joseph L. Corriveau.

This paper was originally presented at the SPIE Defense and Commercial Sensing 2019 Event held in Baltimore, MD and published in the SPIE Proceedings on 14 May 2019. The support on this project included Jason Dorvee, Brandon Booker, Chris Williams, Blaine Morriss, Keran Claffey, Terrance Sobecki, Stephen Newman, Rosa Affleck, Charles Smith, Michele Maxson, Andrew Bernier, and Bonnie Jones. Furthermore, we would like to acknowledge the help and support of Night Vision Labs located in Fort Belvoir, VA.

The Commander of ERDC was COL Teresa A. Schlosser and the Director was Dr. David W. Pittman.

DISCLAIMER: The contents of this report are not to be used for advertising, publication, or promotional purposes. Citation of trade names does not constitute an official endorsement or approval of the use of such commercial products. All product names and trademarks cited are the property of their respective owners. The findings of this report are not to be construed as an official Department of the Army position unless so designated by other authorized documents. 


\title{
SPIE Proceeding: Meteorological property and temporal variable effect on spatial semivariance of infrared thermography of soil surfaces for detection of foreign objects
}

\author{
Austin K. Workman and Jay L. Clausen
}

\begin{abstract}
The environmental phenomenological properties responsible for the thermal variability evident in the use of thermal infrared (IR) sensor systems is not well understood. The research objective of this work is to understand the environmental and climatological properties contributing to the temporal and spatial thermal variance of soils. We recorded thermal images of surface temperature of soil as well as several meteorological properties such as weather condition and solar irradiance of loamy soil located at the Cold Regions Research and Engineering Lab (CRREL) facility. We assessed sensor performance by analyzing how recorded meteorological properties affected the spatial structure by observing statistical differences in spatial autocorrelation and dependence parameter estimates.
\end{abstract}

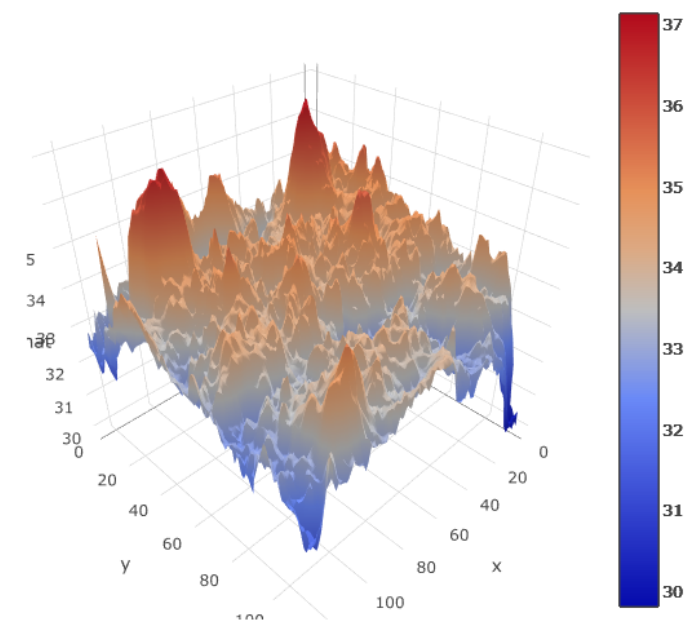

Figure 1. This figure shows a 3 dimensionsal representation of the thermal image recorded from our FLIR thermal imaging technology. The height and color both denote the temperature at the given thermal resolution point 


\section{INTRODUCTION}

The US Army has been testing a variety of sensor systems (thermal IR, seismic, acoustic, radar, electromagnetic) for the detection of landmines and Improvised Explosive Devices (IEDs) at the countermine test site at Yuma Proving Ground (YPG) and other sites and has amassed a significant library of data. Presently, the US Army has spent the last several years developing and testing a variety of computer algorithms to improve the Probability of Detection (PD) of land mines and IEDs. The PD and reduction in False Acceptance Rate (FAR) and have not achieved the necessary objectives for a high confidence system. One reason for this, we hypothesize, is the lack of consideration for the impact of soil and atmospheric phenomenological properties on sensor performance for land mine and IED detection. Techniques for rapidly assessing the location of disturbed soils due to IED emplacement or other elicit activities within a large spatial area are needed by the Army. The coupling of wide area assessment technologies such as IR signatures, magnetic fields, or other spectroscopic sensor modalities with novel geospatial statistical methods is a means to effectively evaluate large spatial areas for soil disturbances. Our approach uses mid- and long-wave infrared imagery for detection of soil disturbances. For example, modern thermal sensors are capable at detecting thermal differences on the fraction of a degree scale. However, the common problem for practical use of this technology is its high rate of false positive detection requiring substantial manual analysis. The research objective of this work is to continue to research and understand the environmental (soil and atmospheric) phenomenological properties affecting temporal and spatial thermal variance of soils. The question being addressed is how to quantify the natural variance "noise" such that it can subtracted from a disturbed area "signal" by taking into account the physical phenomenological material and atmospheric properties. Our research is focused on the variables we have identified as having statistically significant and correlated difference due to variations in thermal irradiation measures for FLIR sensors. Our research will focuses on the interplay of environmanetal processes and thermal behavior.

\section{BACKGROUND}

Historically, electromagnetic sensor systems have been utilized to detect buried ferrous objects. However, buried land mines and IEDS are made out of ferrous and non-ferrous, e.g. plastic materials. With the current conflicts in Afghanistan and Iraq there has been an increased interest in other sensor modalities, e.g. thermal infrared (IR), hyper-spectral imagery, seismic, acoustic, ground penetrating radar, that are capable of detecting buried objects regardless of their material composition. These alternative sensor modalities could be operated independently. Increasingly there is interest in fusion of multiple sensor systems into a single comprehensive platform allowing for complimentary integrative analysis. ${ }^{1}$ Additionally, there is interest in using autonomous UAVs or ground platforms for quickly characterizing and area at standoff distances prior to conducting military patrols, convoys, or combat operations. Another application is using mines/IEDs to shape the battlefield, which requires an understanding of the conditions under which the mines/IEDs are detectable. A landmine is a type of self-contained explosive device that is placed into or onto the ground. They are mainly used as a military tactical weapon against vehicles or people. ${ }^{2}$ Their most common tactical use is to restrict enemy movement in times of war. They serve the same bordering purpose of physical barriers such as barbed wire, however landmines are unique in their ability to be undetectable, which further adds to the importance of sensor modalities and detection methods. ${ }^{3}$

Due to the difficulty of detection, landmines can lay dormant in areas that have long since become demilitarized zones. As of 2003, there was as estimated 70 million active landmines worldwide. ${ }^{4}$ These

landmines have estimated to have caused over one million casualties estimated at 800,000 deaths. ${ }^{5}$ Being able to properly identify areas with prevalent with landmines can help increase safety, decrease maiming and death counts, and increase public sentiment. ${ }^{4,5}$

Laying mines is simple and inexpensive, while in contrast, detecting and removing mines is expensive, difficult, and often dangerous. The goal of new age detection methods is to be able to detect all constructs of mines such as plastic, metal, or wood, in any type of soil, weather, or extenuating condition. The literature has shown that current methods perform with varying accuracy under different conditions with no optimal method yet discovered. ${ }^{6}$ Optimally, the best method would be able to give instantaneous detection with 
negligible amount of false alarms. ${ }^{7}$ Infrared thermography has received increasing interest over the past decade as a sensor modality. ${ }^{8}$ Thermal IR is based on the concept that the thermal signature of soil is altered by objects buried at shallow depths within the soil, regardless of metal content due to an altering of thermodynamic properties. ${ }^{9}$ The technique measures surface-emitted electromagnetic energy in the IR radiation band, also known as thermal radiation. Materials differ in thermal capacities, resulting in different heating and cooling rates and associated infrared emissions. ${ }^{9}$ If a landmine is exposed on the physical surface being imaged, differences in thermal signature will depend on the material of the landmine. In the more likely case that a landmine is buried, the thermal signature of the soil at the surface above and around the mine becomes a complex interplay of many different and unique factors such as, but not limited to, the soil texture and water content,${ }^{10}$ or the depth buried. ${ }^{11}$ There are a lot of methods in development concerning IR sensing technology that look at diurnal cycles, ${ }^{12,13}$ numerical simulations, ${ }^{13,14}$ and meteorological properties ${ }^{12}$ as well.

Many researchers acknowledged consistent challenge in the use of thermal IR for anomaly detection is the heterogeneous nature of soils ${ }^{9}$, which can mask the signature of buried objects due to the high variability of thermal emissions of the soil itself. Soil IR signatures are affected by a host of environmental factors, such as temperature, volumetric water content, material density, reflectance, and surface texture. However, the manifestation of the variability within these factors, and their interactions, are poorly understood. For instance, diurnal thermal fluctuations due to changing solar input throughout the day give rise to thermal contrasts at the surface, but the mechanism of heat and moisture transfer contributing to these contrasts remains unclear and unquantified. ${ }^{15}$ Adding to this complexity is the additional influence of a buried object on both the heat and moisture transfer. ${ }^{15}$ Since thermal imaging as a sensor modality increased in popularity in the early 2000's, multiple papers have taken to studying varying types of properties. ${ }^{8}$ The most common approach taken from other researchers is to hold multiple factor properties constant while adjusting a specific factor of interest in hopes of seeing a discernible pattern in the data output. Van $\operatorname{Dam}^{9}$ discovered that in both dry and wet soils, the texture does not make much difference for the thermal signature of a buried landmine. Van Dam also concluded that water content affects the thermal signature, though the relationship did not have a quantifiable linear relationship. Koenig ${ }^{16}$ published a paper that realized accounting for the properties of disturbed and undisturbed soil can help better detect buried objects. The presence of a buried object disturbs the heat and diffusion parameters of the soil, enabling anomaly detection. ${ }^{15}$ Contrasts in surface temperature are manifested by two phenomena - a volume effect, which results in the soil emissions immediately surrounding buried devices contrasting with background soil, and a surface effect, which reflects the soil disturbance from the physical act of burial. ${ }^{10,15}$ The extent of the volume effect is primarily determined by the characteristics of the object, although the importance of soil volume is negatively correlated with the role of burial depth. ${ }^{15}$ The surface effect remains for weeks after the disturbance and enhances the contrast induced by the buried object. ${ }^{10}$ Waldemar ${ }^{17}$ extended the work of Hong and Van Dam by observing varying contents of water and varying densities of soil on landmine detection at a physical level, supported by numerically simulation. Prediction of expected surface temperatures is complicated by the non-linear movement of water within soil and changes in surface temperature during the drying process. To date, no direct quantifiable relationships have been established relating the environments impact on thermnal sensor performance. Understanding the relationship between meteorological conditions and soil conditions is paramount to being able to detect landmines and IEDs buried in soil.

The best way to understand the interrelationship of 2-dimensional spatially correlated observations, such as pixels in a thermal image, is to observe the spatial variograms. A variogram, denoted $2 \gamma\left(s_{i}, s_{j}\right)$, of a set of spatially correlated observations at locations $\boldsymbol{s}=\left(s_{1}, s_{2}, \cdots, s_{n}\right)$ is defined as the variance between field values at two locations across all realizations of the field, given by the equation;

$$
2 \gamma\left(s_{i}, s_{j}\right)=\operatorname{var}\left(Z\left(s_{i}\right)-Z\left(s_{j}\right)\right)
$$

where $Z\left(s_{i}\right)$ is the observation of thermal temperature at spatial location $s_{i}$. 
Spatial data are data that are collected in space. Spatial data is a realization of a spatial stochastic process, $\{Y(s): s \in D\}$, where $s$ is the location from which the data is observed and $D$ is a random set in $d$-dimensional Euclidean space. Spatial statistical analysis arose not to answer the question "how much", but to answer the question "how much is where". ${ }^{18}$ The basic theory behind spatial statistical methods is the idea that observations in close spatial proximity tend to be more similar than observations that are spatially separated, otherwise known in spatial analysis as autocorrelation. Correlation is defined as a measure of similarity between two difference variables. ${ }^{19}$ Spatial Autocorrelation is the correlation among values strictly attributable to their relatively close proximity. ${ }^{20}$ In spatial statistics this means observations close in Euclidean space, while for time series this means observations close in time.

A Variogram is the most important tool in exploratory spatial analysis. the variogram measures the spatial autocorrleation of a field by describing how sample data are related with regards to distance and direction. We can construct semivariograms of the thermal signatures of out test plot for any FLIR thermal images. Variograms allow us to visualize the spatial structure of the variability of the test plot and how the variability compares across different factors.

\section{EXPERIMENTAL DESIGN}

The experimental design for our project had two different phases to analyze different features of the spatial variance of thermal images. The first phase involved construction of test cell without manipulation of the soil. Not controlling for external factors allowed us to get exploratory readings on how the natural processes of our area affected thermal signature. This provided a baseline for our future phases that controlled for factors such as homogeneity of soil. Phase II involved the construction of test plot using homogenized soil from the plot. In Phase II we emplaced 158 subsurface thermistors and 26 volumetric water content readers to measure how water content and thermal temperature changes across three dimensional space.

\subsection{Phase I}

As mentioned above, the plot is located at CRREL in an area cleared of brush and trees such that the test section incurred nearly full sun all day. The study consisted of two 0.3 meter by 0.3 meter test plots subsetted into $2561 \mathrm{~cm}$ by $61 \mathrm{~cm}$ cells*. One plot was scraped with a surface excavator to remove the surface vegetation exposing bare ground of mineral soil, whereas the second plot had a vegetated strip running down the center. We measured multiple different properties of the soil, but no manipulation of soil was performed. The metal content of the soil was analyzed using x-ray fluorescence (XRF). The analytes included Ag, As, $\mathrm{Co}, \mathrm{Cr}, \mathrm{Cu}, \mathrm{Fe}, \mathrm{Mn}, \mathrm{Mo}, \mathrm{Ni}, \mathrm{Pb}, \mathrm{Sb}, \mathrm{Yi}$, and $\mathrm{Zn}$. Soil samples were taken at various depths. Grain size analysis was conducted following ASTM D422. There were three methods used to measure the density of the in-situ soil; these included the drive cylinder and the EGauge. Surface roughness was measured using a Reigl's VZ400 LIDAR. Throughout both phases, we used a meteorological station to record a multitude of different properties including: air temperature, relative humidity, pressure, wind speed, rain, and short and long solar radiation. Data acquisition was on 15 minute intervals and synchronized to the thermal IR cameras. The met station for phase I was located 50+ meters from the plot, while in phase II the met station was located 13 meters from the plot.

\subsection{Phase II}

Phase II was similar in experimental design to phase I. The changes implemented in phase II were made onto select factors to reduce spatial variability and noise. For phase II, we homogenized the soil down to 65 centimeters below the surface to reduce spatial variability across the $3 \mathrm{D}$ plot. Phase II controlled for the depth of the buried object and the object material by replicating object dimension and material. Furthermore, to obtain a better understanding of the 3-dimensional behavior of the temperature and water content spatial structure, we installed 158 thermistors and 26 water content readers at varying depths and spatial locations. Lastly, we readjusted the FLIR camera to observe a grassy area and a non-homogenized

\footnotetext{
${ }^{*}$ The plot subsetting was only used for analysis purpose, there were no physical barriers dividing the plot
} 
soil area outside the plot area of study to allow for a control of mediums to compare our homogenized soil data analysis.

The size of objects placed below the surface level of the plot were larger in the phase II study

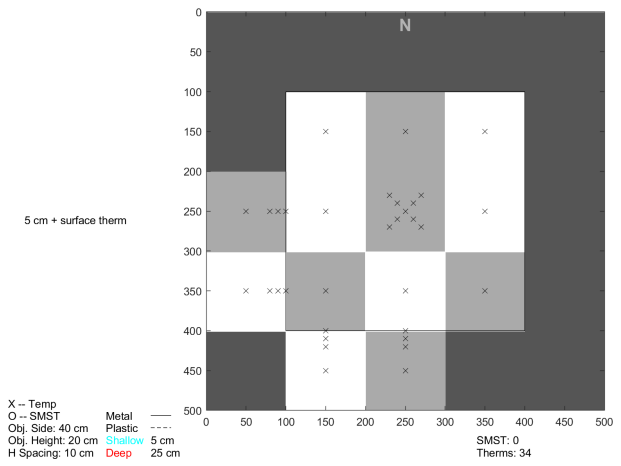

Figure 2. The blueprint of the $5 \mathrm{~cm}$ depth shows the distribution of the thermistors across the Phase II plot design.
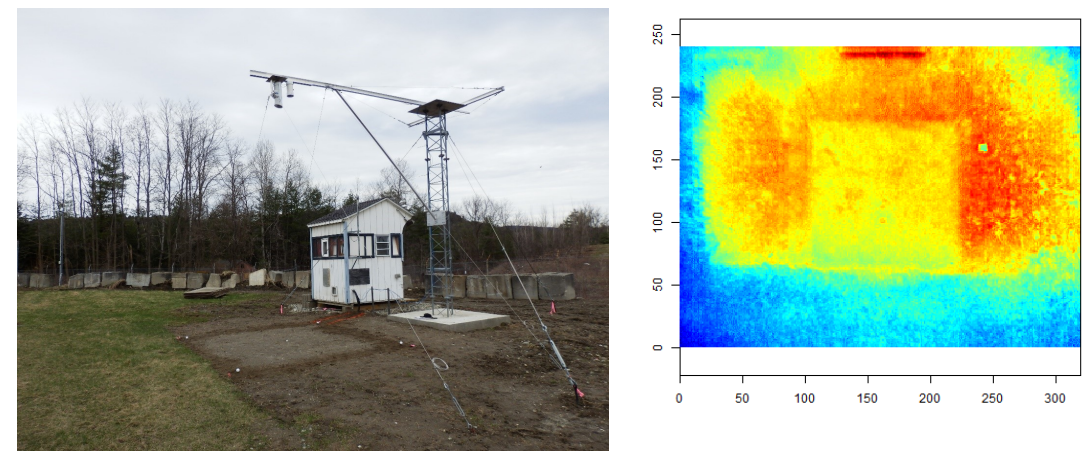

Figure 3. Outdoor plot experimental design and set up with corresponding thermal image 


\section{SPATIAL ANALYSIS}

Previous research has shown a link between weather conditions and meteorological processes effected the spatial distribution of the heat signature of soil surfaces, but our goal of this study is to numerically quantify to what degree each measurable factor contributes in determining the spatial distribution, structure, and numerical output for soil surfaces so we can better understand the ideal conditions to scan for subsurface land mines and IEDs. Quantifying spatial variability will provide a better understanding about how weather interacts with spatial properties.

\subsection{Weather Event ANOVA}

We recorded and catalogued the weather conditions for all days in which we recorded thermal images. We divided the weather event into three distinct categories: "Sunny/Clear", "Cloudy", and "Rain". In an attempt to decrease noise and outlier observations, we only observe days in which there was consistent sunshine or cloud cover or rain throughout the day. As mentioned in section 2, variograms are the best way to obstain 2-dimensional representations of spatial structure and allows us to cross-compare the spatial structures by shape and parameters estimates. Empirical variograms and theoretical variograms were constructed for 23 chosen days. The variograms were constructed from thermal images taken at 10am. The variogram comparison can be see in figure 4 below:

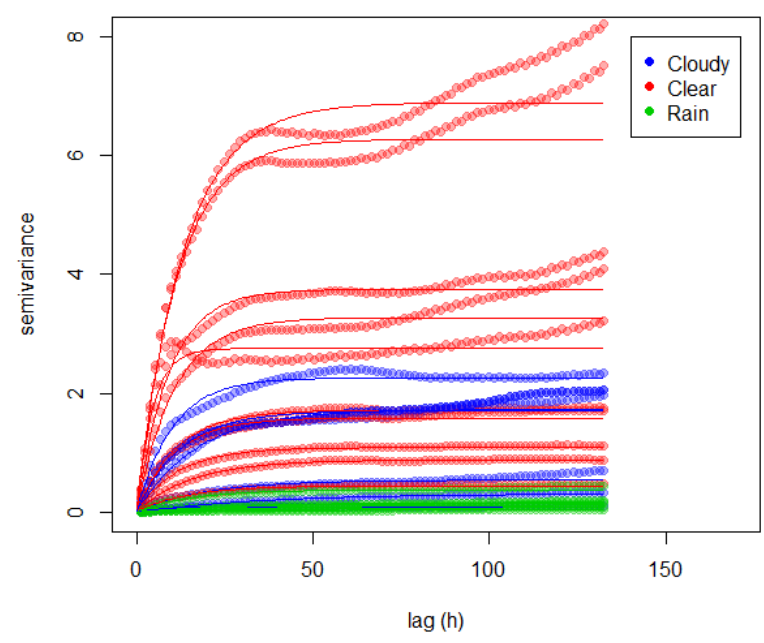

Figure 4. Variograms of selected thermal images by weather event

Next we fit theoretical variograms to calculate spatial parameters that model the spatial structure so that we can compare spatial structure with numerical methods. Tables 1 and 2 are two numerical comparison methods the confirm that the groups are statistically significantly different.

Table 1. One-way ANOVA of sill estimates by weather event

\begin{tabular}{|l|l|l|l|l|l|}
\hline & DF & Sum Sq. & Mean Sq. & F-value & p-value \\
\hline Weather Event & 2 & 31.24 & 17.98 & 19.84 & $2.23 \times 10^{-05}$ \\
\hline Residuals & 19 & 14.96 & 0.79 & & \\
\hline
\end{tabular}


Table 2. Tukey HSD by group analysis

\begin{tabular}{|l|l|l|l|l|}
\hline & diff & lwr & upr & p adj \\
\hline fair-cloudy & 1.35 & 0.22 & 2.49 & 0.0181 \\
\hline rain-cloudy & -1.58 & -2.84 & -0.33 & 0.0122 \\
\hline rain-fair & -2.94 & -4.13 & -1.75 & $<0.001$ \\
\hline
\end{tabular}

\subsection{Phase I object emplacement}

The objects we placed in phase I were widely varying in depth, material, shape, and size, so we were not able to quantify how individual object classifications compare. However we were able to quantify the overall effect of object emplacement on spatial variability. We test whether the object emplacement is affecting maximum spatial variability by observing the pre vs post-emplacement sill estimates with a corresponding analysis of variance (ANOVA). Figure 5 shows the distribution of the spatial sill values of the before and after groups. The tests showed that the pre and post-emplacement variograms are not significantly different by means of parameter estimate comparison. However further tests showed that same thermal image with objects and without objects had statistically significant variograms, evidenced in figure 6 . These conflicting results led us to conclude that objects effect spatial variability of thermal surface temperatures, but we were unable to determine to what degree.

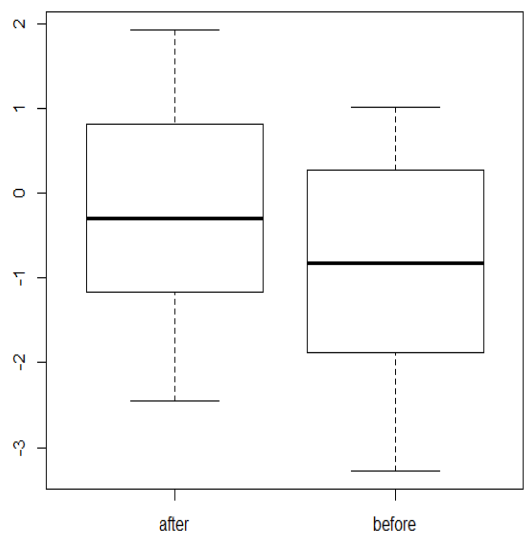

Figure 5. Log-transformed spatial sill and sill parameter estimates for 23 thermal images 

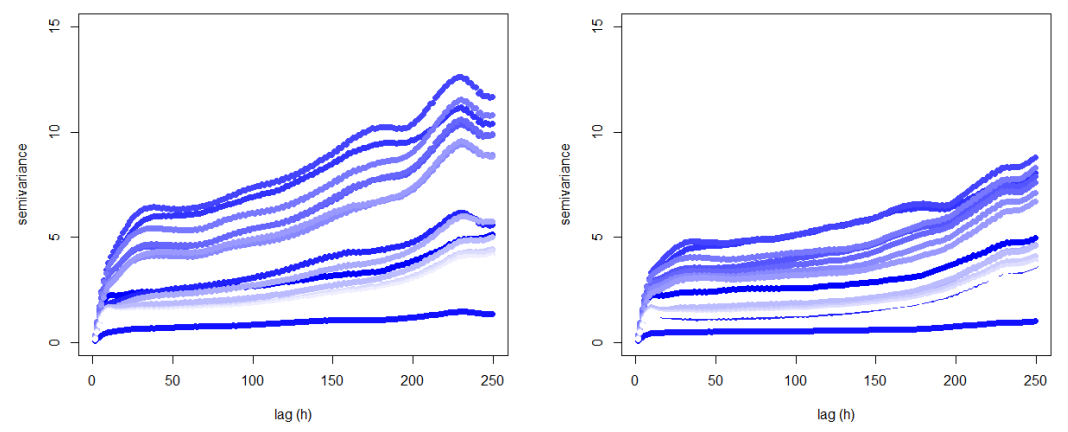

Figure 6. Log-transformed spatial sill and sill parameter estimates for 23 thermal images

\subsubsection{Phase I results, discussion, and conclusion}

From our analysis, we have only statistically proven that weather event causes varying levels of spatial variability, that the diurnal cycle effects maximum spatial variability, and that object emplacement effect the maximum spatial variability. Analysis of individual factors such as shortwave solar radiance and water content were inconclusive due to the data resolution and unknown soil properties.

\subsection{Phase II in-depth meteorological and time factor analysis}

As mentioned in section 3, the Phase 2 analysis of our data had us control for as much noise causing variation as possible, such as homogenizing the soil and controlling the object size and depth. In phase I, we noticed that there was a trend in time of day, weather condition, and the maximum spatial variability, but we were unable to relate them to any numerical factor due to the low resolution of data we observed. In phase 2 , we were able to line up our meteorological data output with the thermal image time stamps to produce graphical representations highlighting the inter-relationship of solar irradiance and spatial thermal variance, shown below in figure 7 and 8 .
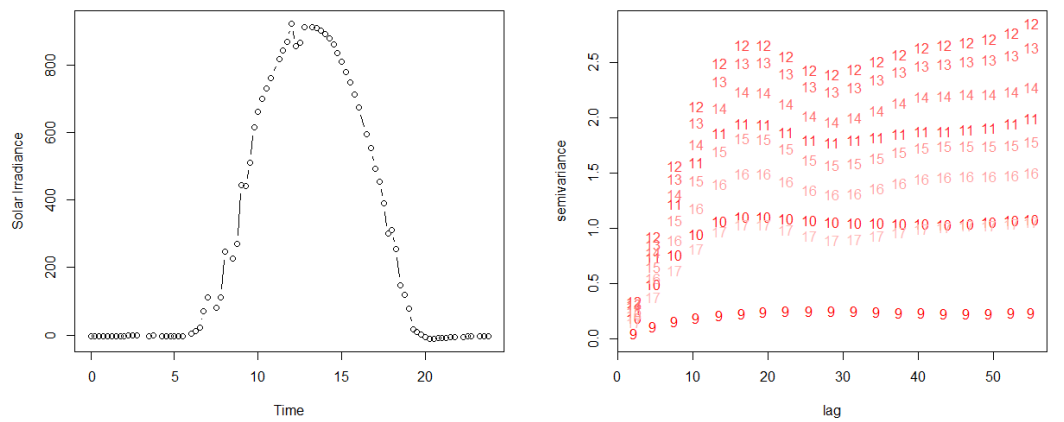

Figure 7. Day with high solar variance and the corresponding spatial variogram by hour 

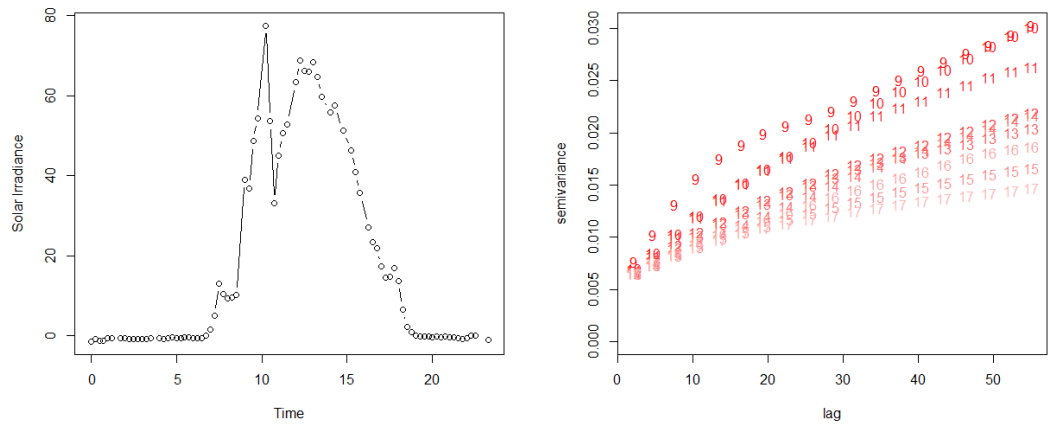

Figure 8. Day with low solar variance and the corresponding spatial variogram by hour

This lead us to believe that there is a relationship between the short wave solar irradiance and the spatial sill and range. More specifically, we hypothesized that high solar irradiance causes the surface to heat areas of high thermal sensitivity, while areas of the plot that have low thermal sensitivity remain low in thermal signature. This process causes the thermal surface to have high contrast, meaning that pixels have high and low readings in close spatial proximity, causing the max spatial variance (sill) to be high and causes the spatial dependent lag (range) to be low.
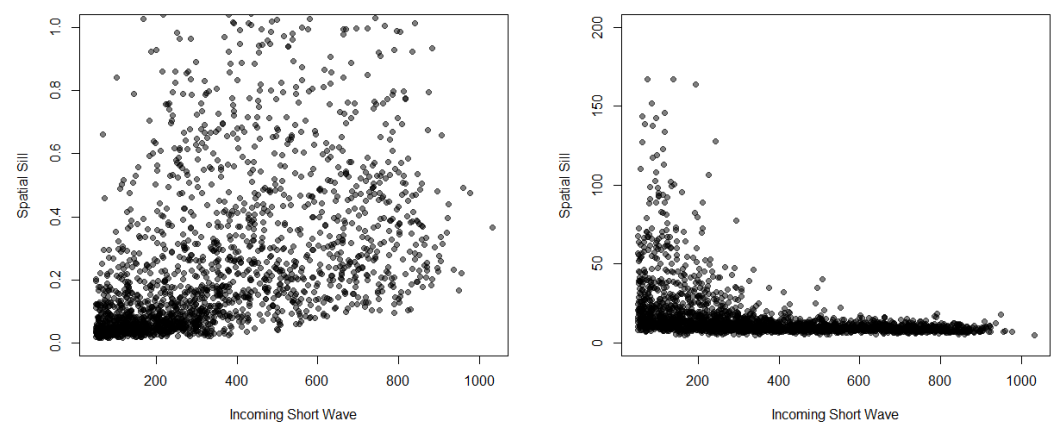

Figure 9. Scatter plot of sill by incoming short wave IR (left) and spatial range by incoming shortwave IR (Right) 

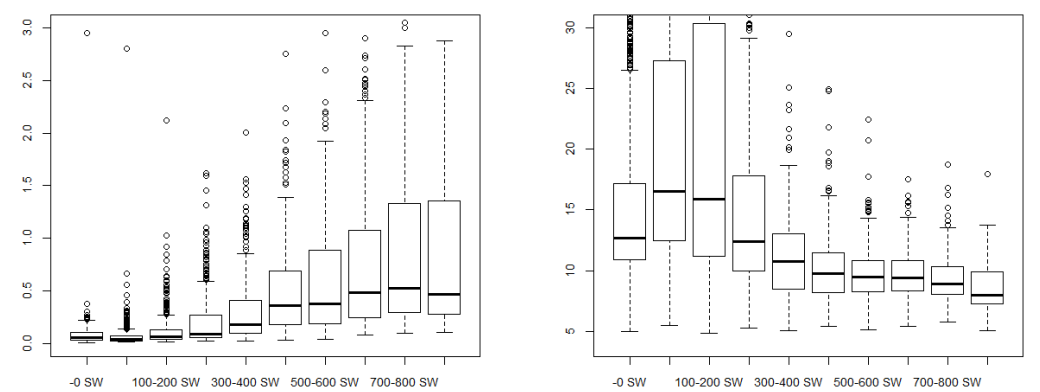

Figure 10. Categorized box-plot representation of scatter plot shown in 9. The solar radiance values are binned into bins of 100 .

Figures 9 and 10 shows that low values of solar radiance correspond with low spatial sill values, while large solar radiance levels correspond to high spatial sill values. These results corroborated future analysis that analyzed time of day concurrently with the amount of solar radiation to determine when the spatial variability is at a level to allow for the clearest visibility for subsurface IEDs.

\subsection{Subplot Temporal Variance}

The plot is divided into the following subplots for the Phase II analysis, shown in figure 11 .

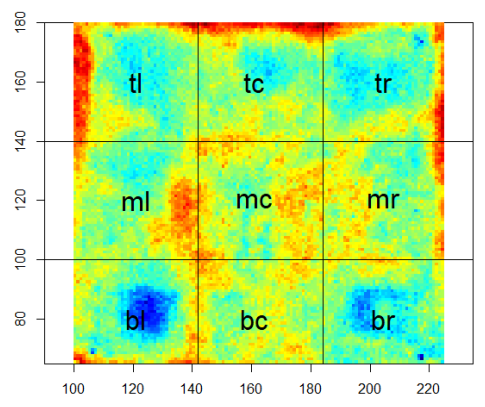

Figure 11. Categorized box-plot representation of scatter plot shown in 9. The solar radiance values are binned into bins of 100 .

In phase 1 , we showed that, on average, the temperature of subplots with objects placed on the surface or underneath the surface was affected and different from subplots without objects. However, we were only able to conclude that temporal variance was by objects, but not what certain properties correlated to the temporal trends due to the variability among object size and materials. Phase II controlled the material, depth, and location of the subsurface objects allowing us to better understand temperature response across time, shown in figure 12 

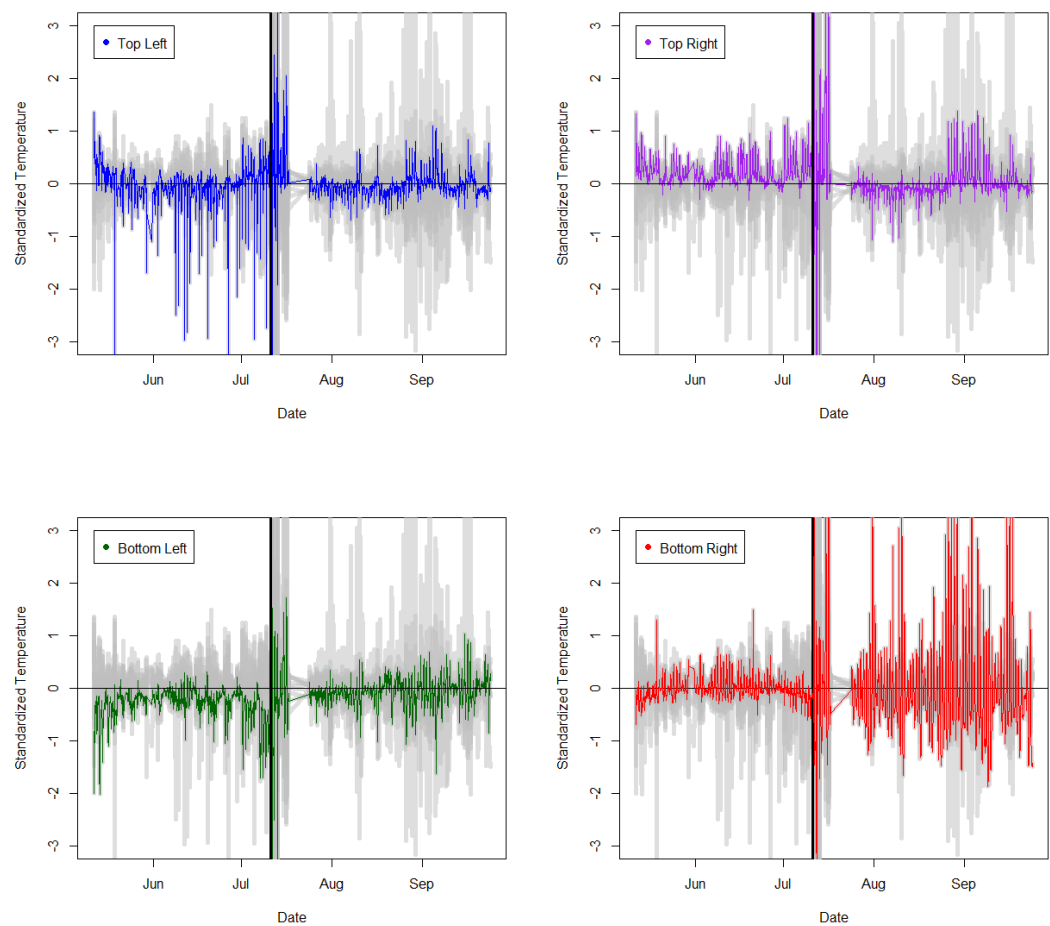

Figure 12. From top left to bottom right: Deep plastic object, deep metal object, shallow metal object, shallow plastic object

Due to the homogeneity of the soil, the placement of the objects causes the thermal temperature readings to change drastically directly after the object emplacement. This trend can be observed most notably in the bottom right subset, which contains a shallowly buried plastic object. Prior to emplacement, the mean temperature deviation seems consistent through time, but the plot experiences a much higher variability in temperature after the object was emplaced. This drastic change in thermal variation can be attributed to the thermodynamic heat flow properties of plastic objects. Each of the objects and depths cause differing trends for each of the subplots containing objects. The subplot containing a plastic object buried deep shows a stabilizing of temperature post placement causing the temperature variation to decrease. The subplot containing a metal object buried deep shows a noticeable negative shift in temperature, meaning the object has a cooling effect on the surface temperature. The subplot containing a shallowly buried metal object shows an increasing trend in thermal signature through time for post placement. These trends are even more accentuated when we look at a subplot containing no buried object shown in figure 13 below: 


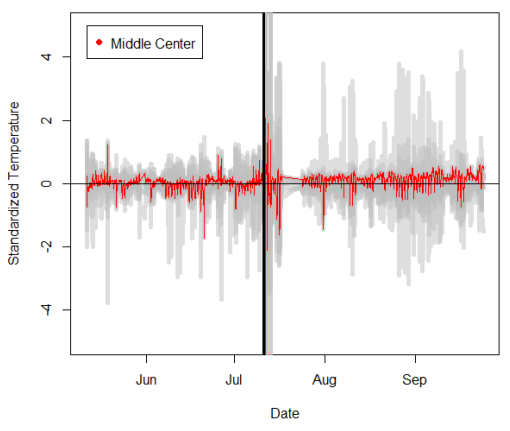

Figure 13. From top left to bottom right: Deep plastic object, deep metal object, shallow metal object, shallow plastic object

\subsection{Object Visibility Measure}

We spent the most of this paper discussing which meteorological properties effect spatial and temporal variance, which has been paramount to help our understanding of detection of buried objects. Now that we know what factors effect spatial variance, we can begin to use those relationships to dive deeper into what it really means for an object to be detectable. For example, does having a large sill or large spatial range mean that contrasts will show spatial anomalies more clearly, or do those spatial conditions wash out any potential object visibility? To assess the problem of variability vs visibility, we decided we need to use features of spatial variability to make a measure of visibility so then we can assess which meteorological properties effect the spatial variance in a way that makes subsurface objects visible. What constitutes as detectable for someone studying thermal images is how easily one can notice unnatural or abnormal change in temperature (often represented as color). Take for instance the following two thermal images, both which have had the objects placed underneath the soil surface.
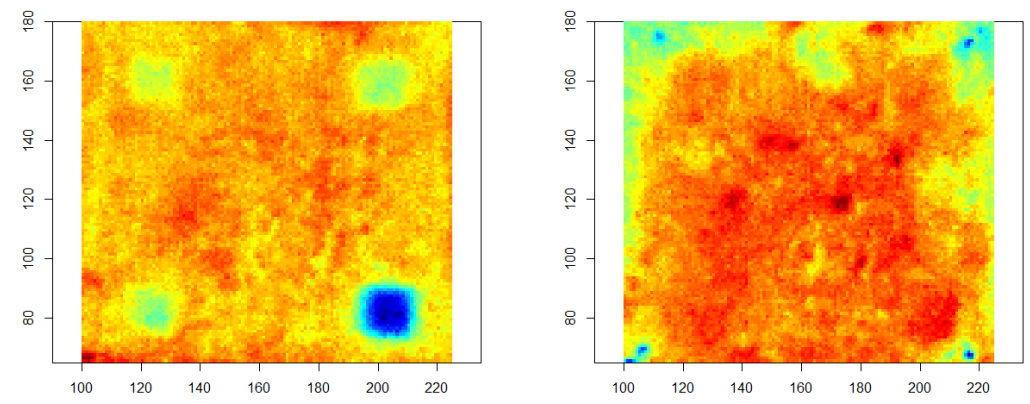

Figure 14. Thermal images

The researcher would look at the left graphic in figure 14 and determine that 4 objects were placed in each of the four corners based on the obscure thermal patterns. Therefore, to assess visibility, a high visibility measure is assigned for each subplot for that thermal image. Conversely, the right graphic in figure 14 has no clear object visibility, thus is assigned a poor visibility measure for each subplot. Our eyes expect there to be smooth gradient change across 2-dimensional space. When sudden drastic changes occur across space, our eyes and minds recognize the unnatural change due to our abilities to recognize patterns. The change that is happening in a numerical sense is a sudden decrease or sudden increase in values of adjacent 
geospatial locations. Variograms measure the average spatial variance for each preset lag distance binned from the shortest distance apart to the max distance apart for all geospatial locations. We use the spatial variance, $\gamma$, at each subplot location, $s_{i}$, as an indication of object visibility. However, being able to see an object is relative to how large the spatial variance of the subplot is in relation to the other subplots and in relation to the overall plot variance. If there is a relatively large spatial variance in a subplot while the overall plot shows little variability, then the gradient of that section will be noticeably different. Thus the equation for recognizing spatial variance is a ratio of how large the maximum or average spatial variation is a compared to the overall plot spatial variance shown in equations 2 and 3 below

$$
\frac{\frac{1}{n} \sum_{i=1}^{n} \gamma\left(s_{i}\right)}{\frac{1}{N} \sum_{i=1}^{N} \gamma(S)}
$$

and

$$
\frac{\sigma^{2}\left(s_{i}\right)}{\sigma^{2}(S)},
$$

Where $\sigma^{2}\left(s_{i}\right)$ is the maximum spatial decay semivariance, or sill, of the subplot $i$, and $\sigma^{2}(S)$ is the sill of the entire plot. We know where the objects are buried, and we take advantage of that fact when dividing the plot into subplots, though these measures would valid even if we were not gifted the knowledge of object location prior to dividing the plot. Because some of the sill and range measurements we obtain are really large, we also created a metric that scales between 0 and 1 as follows

$$
\frac{\frac{1}{n} \sum_{i=1}^{n} \gamma\left(s_{i}\right)}{\frac{1}{N} \sum_{i=1}^{N} \gamma(S)+\frac{1}{n} \sum_{i=1}^{n} \gamma\left(s_{i}\right)}
$$

and

$$
\frac{\sigma^{2}\left(s_{i}\right)}{\sigma^{2}(S)+\sigma^{2}\left(s_{i}\right)},
$$

To validate that this use of spatial variance as a measure of object visibility we observe 5000 thermal images and calculate the visibility metrics. After we obtain these visibility metrics we can test if high visibility metric values correspond to thermal images with obvious objects in the subsurface. by subplot, we get the following distribution of visibility metrics: 

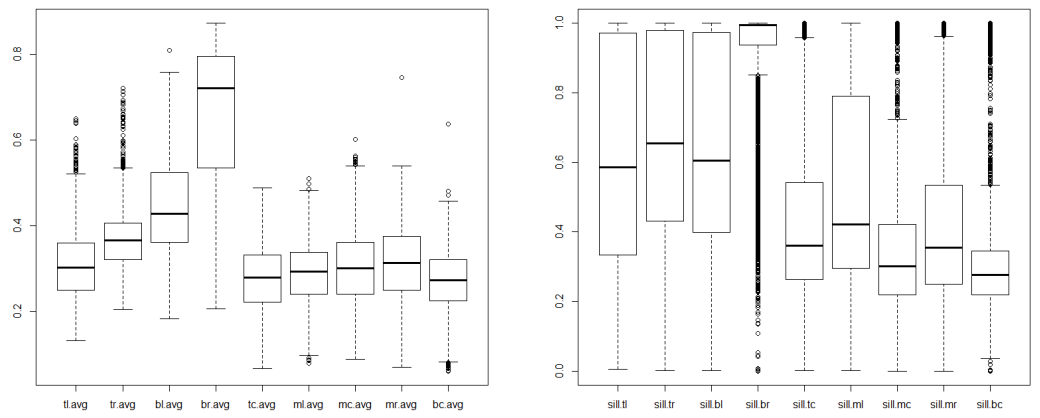

Figure 15. Left are the average semivariance risk ratio (equation 4 values for each subplot. Right are the average sill risk ratio (euqation 5 values for each sublot.

According to the average semivariance ratio (left graphic in 15) the median visibility metric for the top left (deep plastic) and top right (deep metal) subplot are not statistically different in average semivariance visibility ratio from the non-object having plots, but there are several box-plot-determined outliers where these subplots are experiencing high visibility measure. This is extremely important for our study. This lets us know that the deeper objects are difficult to see visibly, on average, but there are certain times and certain conditions where the objects become visible, which we can now attempt to quantify statistically. Next, these box-plots also show that the visibility measure for both the shallow objects was much larger compared to every other subplot with the plastic shallow subplot being significantly larger than even the shallow metal. There are thermal images in which the visibility measure is as low for the shallow objects as for the average subplot, meaning that even shallow objects have conditions it is is essentially invisible in a thermal image.

We decided that we need to quantify the time of the day where the visibility is the highest for each subplot. Once we have quantified time's effect on visibility, we will look further into the variable to see what meteorological conditions are occurring at these high visibility times. Figure 16 above shows the average visibility at every 15 minutes of the day for each subplot. For these averages we found the visibility measure for each of the 4 subplots over 5000 thermal images. The grey represents the average visibility measure for the 5 subplots that do not have any objects. As we see in the shallow plastic object, the visibility measure is larger for every time stamp for the entire day, which is what we expect from observing the thermal images. The shallow plastic image is already known to be highly visible under almost any condition, thus we expect the visibility measure to be universally higher than the average non-object subplot visibility measures. The two deep buried objects are obviously much more difficult to see with thermal images. At some time points, e.g. 10:30 and 20:00, the visibility measure for the deep buried objects are no more visible than the nonobject subplots meaning that we can assume the visibility is poor. Figure 17 below shows the differenced visibility measure for the 4 subplots which help us identify when visibility should be highest for each of the subplots. 

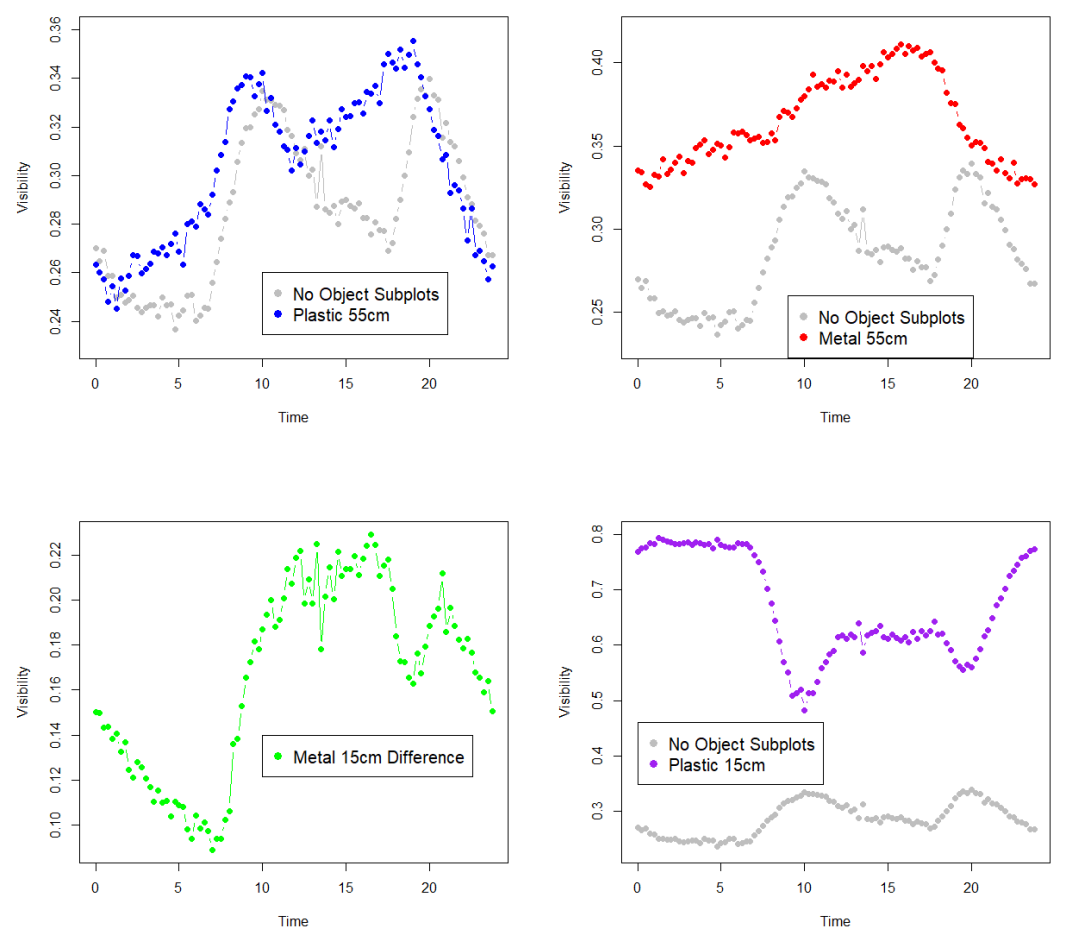

Figure 16. The average visibility metric at a 15 minute increment throughout the day for each object-containing subplot
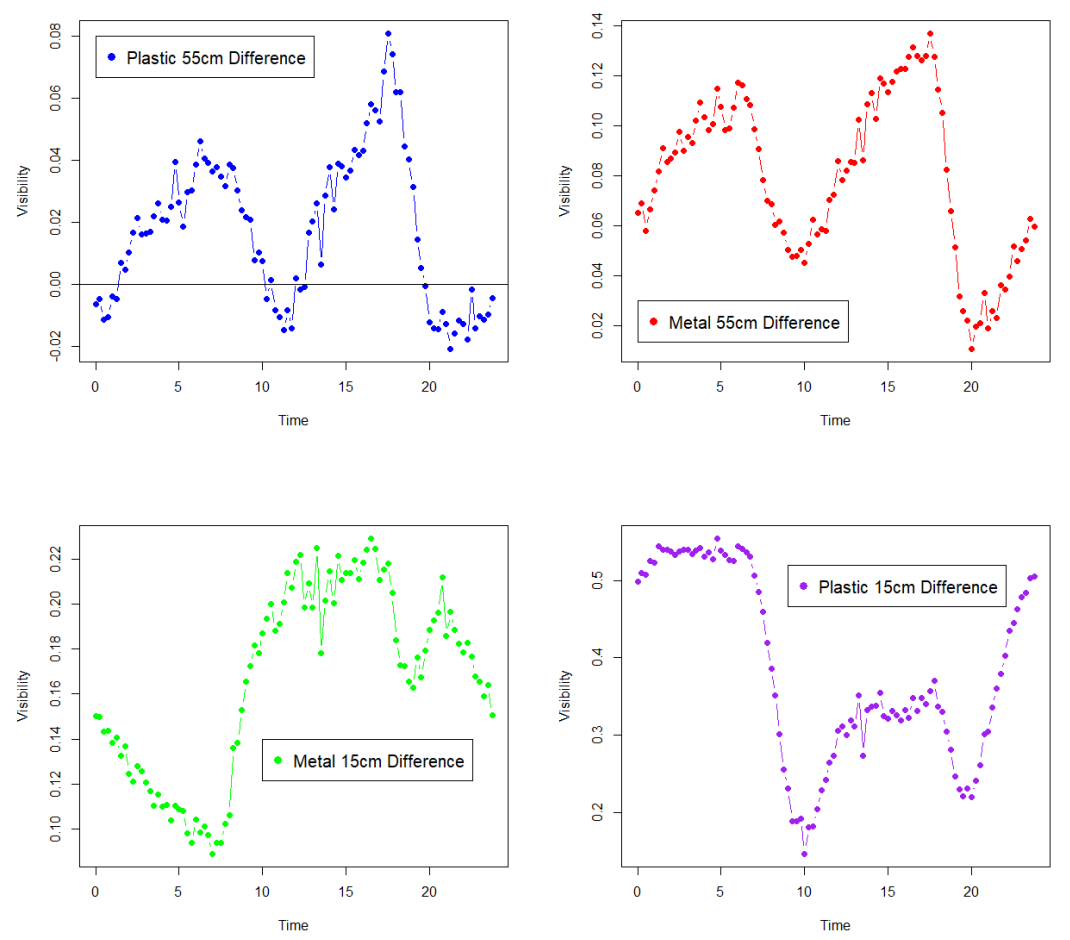

Figure 17. Left: Poor visibility measures for all; Right: Poor visibility for deep mines and shallow metal, average visibility for shallow plastic 
The best time of the day, on average, to see the deep buried objects is between 05:00 and 08:00 and between 15:15 and 19:00. The specificity of this time is very important because the worst times for visibility are very close in time to the best times for visibility, this is a concept of thermodynamic heat flow that is described later in the a discussion section.

Figure 9 and 10 above described how solar irradiance effects spatial parameter estimates. The spatial sill, often interpreted as the maximum spatial variance of geospatial field is directly, although noisily, correlated to incoming solar irradiance. Higher solar irradiance values brought on by intense direct sunlight causes increase in spatial thermal variance of the soil surface. The spatial range is the distance apart that two geospatial points reaches the maximum spatial variance and is often interpreted as the distance apart that geospatial points stop showing spatial correlation. The spatial range decreases as the solar irradiance increases. This means as the soil surface is exposed to direct sunlight for extended periods, geospatial points are correlated at shorter distances and the contrast increases across the soil surface. Low spatial range values correlate to a more uniform thermal image.

The highest visibility measure for the shallow plastic object corresponds to when there is 0 (zero) solar irradiance, which matches with the time of day graphic in the previous section. There is no solar irradiance at night. The visibility metric for the shallow plastic was highest during the nighttime and sunless hours of 22:00 to 05:00. Thus we see the compounding evidence that lower solar irradiance levels and early day hours correspond to high visibility marks for the shallow plastic object subplot. The shallow metal object is most visible during the middle times of the day and is least visible during the early and late hours of the day. There also appears to be a dip in visibility measure at 19:00. On average, the object is most visible at high solar irradiance levels and is least visible at low solar irradiance values. At times when there is typically high solar irradiance 10:00 - 17:00, we get the best visibility measure. We conclude that solar irradiance has an effect on visibility but under some constraints of time. Furthermore, we see the "washout effect" discussed earlier when the solar irradiance is abnormally high. At peak sunlight hours when there has been constant sun exposure leading to incoming solar IR readings in the $800 \mathrm{~s}$, the entire plot becomes so hot that any thermal signature is completely washed out. Not surprisingly, looking at just the solar irradiance does not tell a lot about the deeper buried objects subplots. The objects are so deeply buried the sunlight doesn't have the same thermodynamic effect. From the time variable analysis, there is only a short window of time in which the deeper objects are visible, and those times correspond to times of high variability of solar irradiance. For the time frame from 10:00 to 12:00, there are no large visibility measure values. For the 16:00 - 19:00 time frame there are several large visibility measures. We conclude that there are conditions during the 16:00-19:00 time frame that cause an increase in visibility that we can attempt to quantify. Conversely, high solar irradiance times never allows for high visibility for the deep object subplots, under any condition. In other words, high solar irradiance completely renders deep buried objects invisible to thermal imaging technology regardless of other known significant factors. 

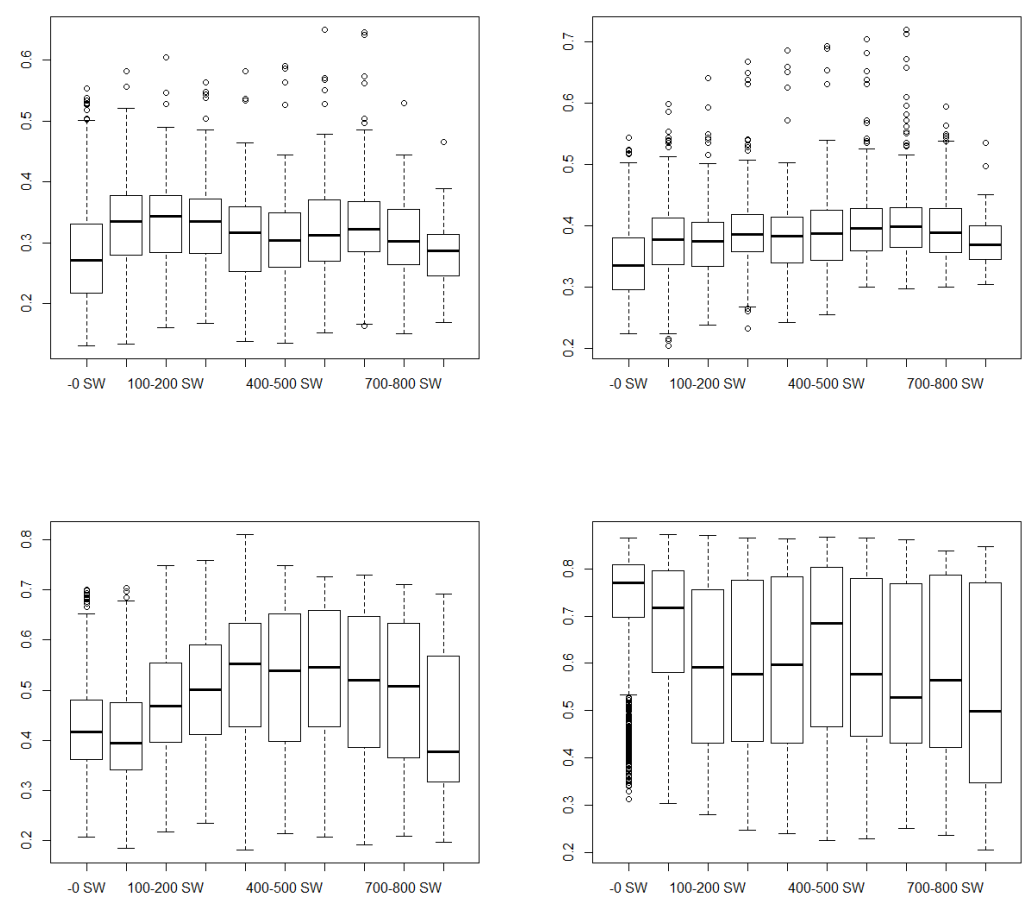

Figure 18. Left: Poor visibility measures for all; Right: Poor visibility for deep mines and shallow metal, average visibility for shallow plastic

\subsection{Rain and Water Content}

Rain events that saturate the top level of the soil with water increase the visibility measure for deeper buried objects. The thermodynamic heat flow predicts this behavior. The deeper objects will be heated to a steady state temperature similar to the surface and surrounding layers. Once a sudden rain event occurs and rapidly cools the surface soil, the deeper layer objects remain heated to the high ambient temperature until the water soaks in to the lower layers. Thus, as we see in figures 19 and 20, the visibility measure is at its highest in the time series directly when the rain is falling and the surface water content is high, but the deep water content is still low.

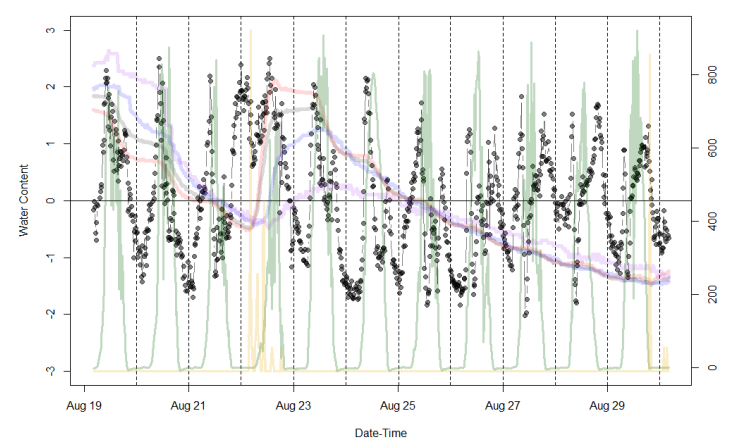

Figure 19. Top Left: Deep Plastic 


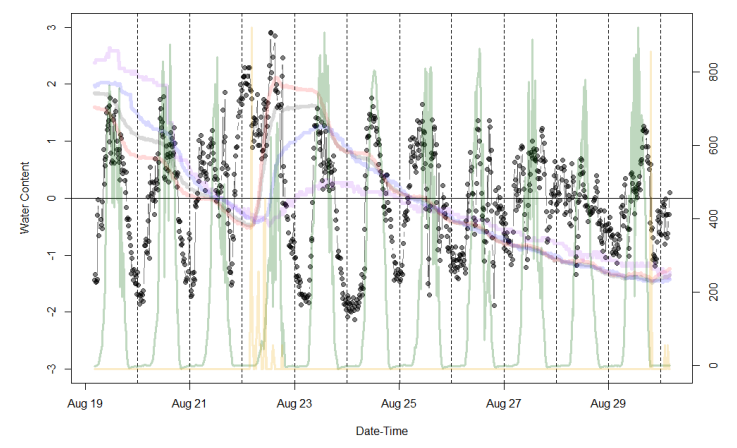

Figure 20. Top Right: Deep Metal

After the rain event on the 22nd of August 2018, it does not rain again for the following 7 days, and the solar irradiance is very high at readings upwards of 800 . The water content begins decreasing as it is evaporating out of the soils. The visibility measure for both deep buried objects then becomes much noisier and unpredictable and slowly decreases back towards its mean visibility that of which is very poor, comparatively. Water content has an opposite effect on the shallow buried objects. The moment of the rain event, the visibility measure for both the shallow metal and plastic object drops and becomes increasingly noisy and volatile. For the shallow metal we see a complete paradigm shift in detection for the days directly following the rain event. The shallow metal object is most visible during daylight hours from 11:00-17:00, on average. However the 23rd -25th (the days directly preceding the rain event) show poor visibility during daylight hours and increased visibility during night hours. Four days after the rain event, we see the metal object return to its natural state and it has high visibility measures again during 11:00-17:00 hours. Furthermore, the 26th-29th see higher max visibility measures for each consecutive day a trend more easily noticeable in 23. Each consecutive day, the incoming Shortwave IR increases and the WC decreases. The thermodynamics suggest that days of consecutive and consistent sunlight will increasingly heat the shallow metal object making its signature more distinctive. The shallow plastic object behaves very similarly to the shallow metal object. The 23rd and 24th of August show very low visibility measures during the daylight hours. The 25th onward have high visibility measures for daylight hours as the system returns to its natural state. Although the daylight visibility measure for the shallow plastic is clearly affected by rain events, the object remains highly visible at night and early morning hours despite the rain. The visibility for the shallow plastic is high under most circumstances, however after rain events, shallow objects are harder to see in a thermal image taken during daylight hours. For metal objects it took 3 days to return to the natural state, and for plastic object it took 2 days to return to its natural state

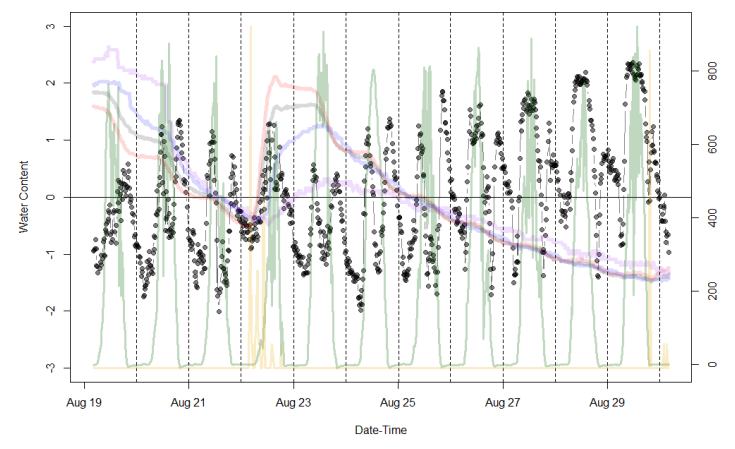

Figure 21. Bottom Left: Shallow Metal 


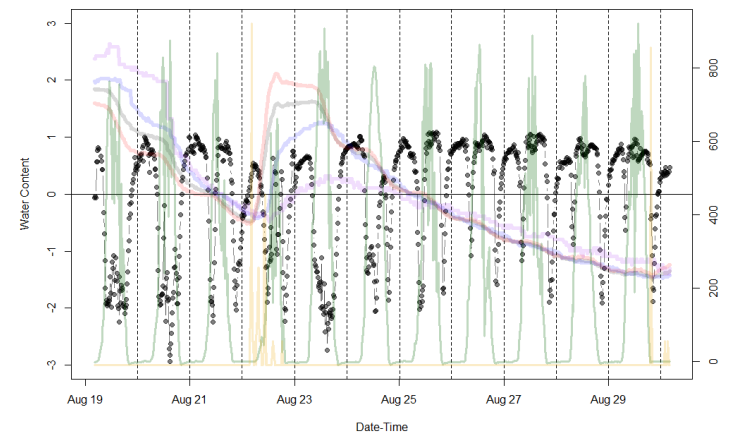

Figure 22. Bottom Right: Shallow Plastic
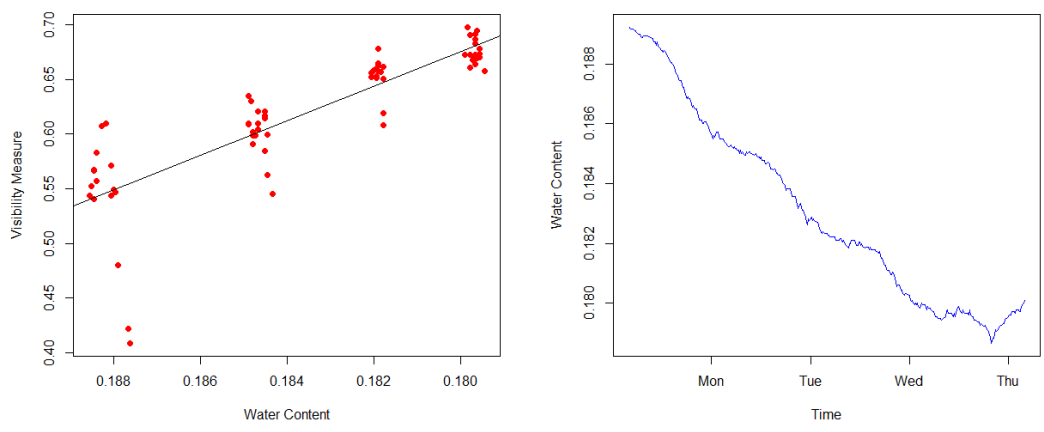

Figure 23. Deep Metal subplot visibility measure as water content decreases for consecutive days

\section{CONCLUSION}

Our initial analysis showed us that weather events changed the thermal signature of the soil surface enough to see statistical differences in spatial structure by multiple different parameter estimates. We saw that sunny clear days showed a much higher maximum spatial variance and a much shorter spatial range culminating in a spatial structure buried objects had high contrast. Conversely we observed that rain washed out the thermal signature of the soil and thus decreased the maximum spatial variance and increased the spatial range. Rain events cause the thermal signature to show little contrast giving the look of an evenly distributed temperature across the entire soil surface.

Our exploratory analysis in phase I led to a quantification of the relationship between buried objects and soil surface thermography and spatial structure. There is a statistically significant decrease in thermal variance when objects are removed from the analysis of the thermal images. This means that on average, there will be an increase in thermal variance if there are objects on or below the soil surface.

Phase II saw us dive deeper into the statistical relationships between weather, objects, time and spatial structure of thermal images. High solar radiation days with diurnal cycles mirroring temperature diurnal cycles track and scale thermal signature variograms in the same diurnal pattern. As the solar radiance gets larger, the variogram sill increases and the spatial variability increases. As the solar radiance begins to decrease, so too does the spatial sill and variance. On days with low solar radiance, the soil surface thermal signature remains muted and causes the variograms to drastically decrease in sill and spatial variance. When the solar radiance is low, the variograms also lose the diurnal pattern. Any spike in solar radiance causes jumps is spatial variance, but without continued exposure of sunlight, the variograms remain low. 
These statistical evaluations were validated by looking at scatterplots and categorized box-plots of spatial parameters vs solar IR shortwave measurements. The graphical trends were proven with statistical tests showing statistically conclusive results $(P<0.0001)$. Phase II expanded on the phase I results that objects increased spatial variance by looking at time series of soil surface temperature difference before and after placement of subsurface buried objects. Depth of buried object and material properties effect the temperature variance differently. Temperature variation was minimized for deep buried objects with the deep metal object having a noticeable cooling effect. The shallow plastic object caused the soil surface to experience greater variation. The shallow metal object initially showed no effect, but as time passed, the signature of that subplot increased in temperature at a steady linear rate.

All of the meteorological and temporal analysis culminated in our use of statistical variability as a measure of object visibility and the analysis correlating meteorological properties and time to high and low moments of object visibility in thermal images. Our conclusions from our visibility metric analysis were in line with previously observed output. The shallow objects experienced much larger visibility measures, on average. This coincided with our analysis of temporal variation that showed the shallow plastic subplots experience much wilder variations from the mean compared to every other subplot. Furthermore, we were able to identify the peak time and peak solar radiance and weather conditions for determining the visibility of objects. Night time hours work well for shallow plastic, midday hours work well for shallow metal, and the moments of sunrise and sunset are best for visibility of deep objects during a series of clear days. Rain and water content has a contrasting washout effect on visibility.

\section{ACKNOWLEDGMENTS}

This project was made possible by the ERDC T-15 funding. The support staff on this project included Jay Clausen, Jason Dorvee, Brandon Booker, Chris Williams, Blaine Morriss, Keran Claffey, Terrance Sobecki, Stephen Newman, Rosa Affleck, Charles Smith, Michele Maxson, Andrew Bernier, and Bonnie Jones. Furthermore we would like to acknowledge the help and support of Night Vision Labs located in Fort Belvoir, VA.

\section{REFERENCES}

[1] Varshney, P. K. et al., "Optimal data fusion in multiple sensor detection systems," IEEE Transactions on Aerospace and Electronic Systems (1), 98-101 (1986).

[2] Frost, M., "Land mine," (2006).

[3] Forum, B. S. . D., "Land mine: History, use, and variants," (2006).

[4] U.S. Department of State, B. o. P.-M. A., "Hidden killers: The global landmine crisis," Washington, $D C, 4$ (1998).

[5] Teague, G. E., "Antipersonnel landmines: A us policy-making minefield," Case Studies in Policy Making , 49-59 (2002).

[6] Bello, R., "Literature review on landmines and detection methods," Frontiers in Science 3(1), 27-42 (2013).

[7] Hussein, E. M. and Waller, E. J., "Landmine detection: the problem and the challenge," Applied Radiation and Isotopes 53(4-5), 557-563 (2000).

[8] Kylili, A., Fokaides, P. A., Christou, P., and Kalogirou, S. A., "Infrared thermography (irt) applications for building diagnostics: A review," Applied Energy 134, 531-549 (2014).

[9] Van Dam, R. L., Borchers, B., Hendrickx, J. M., and Hong, S.-h., "Soil effects on thermal signatures of buried nonmetallic landmines," Detection and Remediation Technologies for Mines and Minelike Targets VIII 5089, 1210-1219 (2003).

[10] Hong, S.-h., Miller, T. W., Borchers, B., Hendrickx, J. M., Lensen, H. A., Schwering, P. B., and Van Den Broek, S. P., "Land mine detection in bare soils using thermal infrared sensors," Detection and Remediation Technologies for Mines and Minelike Targets VII 4742, 43-51 (2002). 
[11] de Jong, W., Lensen, H. A., and Janssen, Y. H., "Sophisticated test facility to detect land mines," Detection and Remediation Technologies for Mines and Minelike Targets IV 3710, 1409-1419 (1999).

[12] Simard, J.-R., "Improved landmine detection capability (ildc): systematic approach to the detection of buried mines using passive ir imaging," Detection and Remediation Technologies for Mines and Minelike Targets 2765, 489-501 (1996).

[13] Sendur, I. K. and Baertlein, B. A., "Numerical simulation of thermal signatures of buried mines over a diurnal cycle," Detection and Remediation Technologies for Mines and Minelike Targets V 4038, $156-168$ (2000).

[14] Pregowski, P., Swiderski, W., Walczak, R., and Lamorski, K., "Buried mine and soil temperature prediction by numerical model," Detection and Remediation Technologies for Mines and Minelike Targets $V$ 4038, 1392-1404 (2000).

[15] DePersia, A. T., Bowman, A. P., Lucey, P. G., and Winter, E. M., "Phenomenology considerations for hyperspectral mine detection," Detection Technologies for Mines and Minelike Targets 2496, 159-168 (1995).

[16] Koenig, G., Koh, Y., Howington, S., and Scott, C., "Phenomenology of thermal signatures of disturbed and undisturbed soils," Detection and Sensing of Mines, Explosive Objects, and Obscured Targets XIII 6953, 69530Q (2008).

[17] Swiderski, W., Hlosta, P., Jarzemski, J., Szugajew, L., and Usowicz, J., "Role of moisture and density of sand for microwave enhancement of thermal detection of buried mines," Detection and Sensing of Mines, Explosive Objects, and Obscured Targets XVII 8357, 83570P (2012).

[18] Schabenberger, O. and Gotway, C. A., [Statistical methods for spatial data analysis], CRC press (2010).

[19] Clifford, P., Richardson, S., and Hémon, D., "Assessing the significance of the correlation between two spatial processes," Biometrics, 123-134 (1989).

[20] Griffith, D. A., [Spatial autocorrelation and spatial filtering: gaining understanding through theory and scientific visualization], Springer Science \& Business Media (2013). 


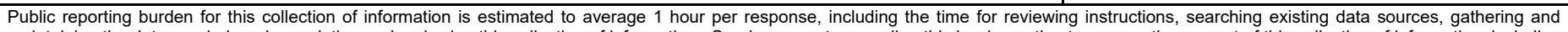

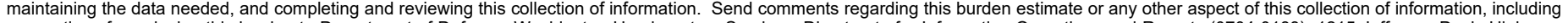

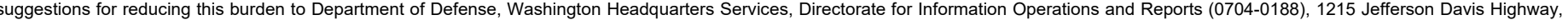

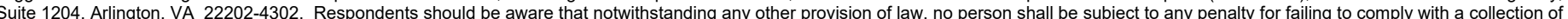

information if it does not display a currently valid OMB control number. PLEASE DO NOT RETURN YOUR FORM TO THE ABOVE ADDRESS.

\begin{tabular}{l|l|l|}
$\begin{array}{l}\text { 1. REPORT DATE (DD-MM-YYYY) } \\
\text { June 2021 }\end{array}$ & $\begin{array}{l}\text { 2. REPORT TYPE } \\
\text { Final }\end{array}$ & . \\
\hline
\end{tabular}

\section{TITLE AND SUBTITLE}

Meteorological Property and Temporal Variable Effect on Spatial Semivariance of Infrared Thermography of Soil Surfaces for Detection of Foreign Objects

3. DATES COVERED (From - To)

5a. CONTRACT NUMBER

5b. GRANT NUMBER

5c. PROGRAM ELEMENT NUMBER

6. AUTHOR(S)

5d. PROJECT NUMBER

Austin K. Workman and Jay L. Clausen

5e. TASK NUMBER

5f. WORK UNIT NUMBER

7. PERFORMING ORGANIZATION NAME(S) AND ADDRESS(ES)

U.S. Army Engineer Research and Development Center

8. PERFORMING ORGANIZATION REPORT NUMBER

Cold Regions Research Engineering Laboratory

72 Lyme Road

ERDC/CRREL MP-21-3

Hanover, NH 03755

9. SPONSORING / MONITORING AGENCY NAME(S) AND ADDRESS(ES)

Headquarters, U.S. Army Corps of Engineers

Washington, DC 20314-1000

10. SPONSOR/MONITOR'S ACRONYM(S)

USACE

11. SPONSOR/MONITOR'S REPORT NUMBER(S)

\section{DISTRIBUTION / AVAILABILITY STATEMENT}

Approved for public release; distribution is unlimited.

\section{SUPPLEMENTARY NOTES}

This paper was originally published on 14 May 2019 in the SPIE Proceedings for the Defense + Commercial Sensing Event held in Baltimore, MD.

This project was made possible by the ERDC T-15 funding.

\section{ABSTRACT}

The environmental phenomenological properties responsible for the thermal variability evident in the use of thermal infrared (IR) sensor systems is not well understood. The research objective of this work is to understand the environmental and climatological properties contributing to the temporal and spatial thermal variance of soils. We recorded thermal images of surface temperature of soil as well as several meteorological properties such as weather condition and solar irradiance of loamy soil located at the Cold Regions Research and Engineering Lab (CRREL) facility. We assessed sensor performance by analyzing how recorded meteorological properties affected the spatial structure by observing statistical differences in spatial autocorrelation and dependence parameter estimates.

\section{SUBJECT TERMS}

Thermal infrared, Thermal imaging, Spatial statistics, Meteorological, thermography, detection, IED

\section{SECURITY CLASSIFICATION OF:}

\section{a. REPORT}

Unclassified

\section{b. ABSTRACT}

Unclassified

\section{c. THIS PAGE}

Unclassified
17. LIMITATION OF ABSTRACT

SAR

\section{NUMBER} OF PAGES

26 19a. NAME OF RESPONSIBLE PERSON 19b. TELEPHONE NUMBER (include area code) 